\title{
Physical and Mechanical Properties of Cementitious Specimens Exposed to an Electrochemically Derived Accelerated Leaching of Calcium
}

\author{
Arezou Babaahmadi ${ }^{1), *}{ }^{\infty}$, Luping Tang ${ }^{1)}$, Zareen Abbas $^{2)}$, and Per Mårtensson ${ }^{3)}$
}

(Received October 28, 2014, Accepted August 5, 2015, Published online August 22, 2015)

\begin{abstract}
Simulating natural leaching process for cementitious materials is essential to perform long-term safety assessments of repositories for nuclear waste. However, the current test methods in literature are time consuming, limited to crushed material and often produce small size samples which are not suitable for further testing. This paper presents the results from the study of the physical (gas permeability as well as chloride diffusion coefficient) and mechanical properties (tensile and compressive strength and elastic modulus) of solid cementitious specimens which have been depleted in calcium by the use of a newly developed method for accelerated calcium leaching of solid specimens of flexible size. The results show that up to 4 times increase in capillary water absorption, 10 times higher gas permeability and at least 3 times higher chloride diffusion rate, is expected due to complete leaching of the Portlandite. This coincides with a $70 \%$ decrease in mechanical strength and more than $40 \%$ decrease in elastic modulus.
\end{abstract}

Keywords: nuclear waste management, service life, concrete, mechanical properties, leaching, acceleration.

\section{Introduction}

In repositories for nuclear waste, concrete and other cementitious materials are extensively used in both the structural components such as the barrier construction and to fill the voids between the waste containers inside the barrier construction. During the very long periods of time considered in an analysis of the long term safety of such a repository exchange of ions between the cementitious materials and the surrounding groundwater (Berner 1992; Reardon 1992) due to concentration differences will occur. This will result in dissolution or precipitation of minerals, and consequently in alteration of the microstructure as well as the chemical and mineralogical composition of the cementitious materials. There are a lot of concerns in normal constructions such as chloride corrosion of the reinforcement, carbonation

\footnotetext{
${ }^{1)}$ Division of Building Technology (Building Materials), Chalmers University of Technology, Gothenburg, Sweden.

*Corresponding Author;

E-mail: arezou.babaahmadi@chalmers.se

${ }^{2)}$ Department of Chemistry, University of Gothenburg, Gothenburg, Sweden.

${ }^{3)}$ Division of Low and Intermediate Level Nuclear Waste, Swedish Nuclear Fuel and Waste Management Company, Stockholm, Sweden.

Copyright ( $\odot$ The Author(s) 2015. This article is published with open access at Springerlink.com
}

or sulfate attack (Morga and Marano 2015; Park and Choi 2012; Pham and Prince 2014; Pritzl et al. 2014), however, here the most important process is the decalcification of the material through the dissolution of the calcium hydrates (Portlandite $\mathrm{Ca}(\mathrm{OH})_{2}$ and the Calcium silicate hydrates (CSH) phases, which constitute the major portion of hydrated cementitious material (Hinsenveld 1992).

Safety assessments of repositories for low and intermediate level radioactive waste (LILW), require prediction of changes in the properties of the cementitious barriers over a very long period of time, up to 100,000 years. In order to improve the accuracy and reduce the uncertainties of the assessments a detailed understanding of the processes occurring in the repository and their effect on the properties of the cementitious materials is of great importance.

The effect of degradation on the properties of cementitious materials has been reported in several studies in the literature (Adenot and Buil 1992; Carde et al. 1997; Carde and François 1997; Carde et al. 1996; Faucon et al. 1996, 1998; Haga et al. 2005; Maltais et al. 2004). In these studies leaching of calcium from cementitious materials have been accomplished both through immersion of the solid cementitious specimens in water (Faucon et al. 1996; Haga et al. 2005; Mainguy et al. 2000) and through immersion of the specimens in chemical agents in order to accelerate the leaching process (Adenot and Buil 1992; Carde and François 1997; Faucon et al. 1996, 1998; Haga et al. 2005; Heukamp et al. 2001; Mainguy et al. 2000; Maltais et al. 2004; Revertegat et al. 1992; Ryu et al. 2002; Saito et al. 1992; Wittmann 1997). The results in these studies indicate that a layered structure is developed in the leached samples comprising an unaltered core delineated by total 
dissolution of Portlandite followed by different zones separated by dissolution/precipitation fronts and progressive decalcification of the CSH gel (Adenot and Buil 1992). Moreover, it is concluded that depletion in calcium changes the bulk density and the pore structure of the hydrated cement paste (Haga et al. 2005; Mainguy et al. 2000) and the changes in pore volume also alters the mechanical properties of the cementitious materials (Carde and François 1997; Heukamp et al. 2001; Saito and Deguchi 2000).

However, although some important conclusions have been drawn from these studies regarding in particular the chemical properties of the $\mathrm{Ca}$-depleted materials, they have been limited to the use of crushed materials or small solid samples. This has limited the possibilities to study the mechanical and physical properties, e.g. compressive strength and diffusivity, which require the use of larger samples. In addition it should be noted that there are not many studies reported in the literature with implication of concrete specimens (Choi and Yang 2013; Marinoni et al. 2008; Nguyen et al. 2007; Sellier et al. 2011) of proper size but instead paste specimens or powder samples have been used (Adenot and Buil 1992; Carde and François 1997; Carde et al. 1996; Faucon et al. 1996, 1998; Haga et al. 2005; Heukamp et al. 2001; Maltais et al. 2004; Revertegat et al. 1992; Ryu et al. 2002; Saito and Deguchi 2000; Ulm et al. 2003; Wittmann 1997).

Finally, although the common feature for both natural and accelerated leaching scenarios will be a total dissolution of Portlandite and a significant decalcification of the CSH phases, other effects of the aging processes may differ considerably between specimens aged by different acceleration methods and comparably natural leaching methods. This emphasizes the importance of reproducing accelerating tests and characterizing the aged samples to account for the comparability of the ageing function of different methods in order to demonstrate properties of degraded cementitious materials.

All this implies that effective acceleration methods with comprehensible kinetics, simulating the natural calcium leaching process for concrete specimens with a size suitable for further evaluation of the mechanical and physical properties of the specimens are needed. In order to comply with this requirement a new method for accelerated leaching of cementitious materials is developed and utilized in this study.

This paper presents the results from the study of the changes in mechanical and physical properties of solid cementitious specimens which have been depleted in calcium. The following properties have been studied: tensile strength, elastic modulus, permeability and water absorption. In addition, the chloride diffusion coefficient of concrete specimens has been studied in order to give an indication of the transport properties of the specimens.

\section{Materials and Methods}

\subsection{Specimen Preparation}

The paste specimens were cast from a mixture of Swedish structural Portland cement for civil engineering
(CEM I 42.5N MH/SR3/LA) and deionized water at a water-cement ratio of 0.5 . The chemical composition of the cement is listed in Table 1. Fresh cement paste was cast in acrylic cylinders with an internal diameter of $50 \mathrm{~mm}$ and a length of $250 \mathrm{~mm}$. The cylinder's ends were sealed with silicone rubber stops. The cylinders containing fresh paste were rotated longitudinally at a rate of $12-14 \mathrm{rpm}$ for the first $18-24 \mathrm{~h}$ of hydration in order to produce specimens with a homogeneous composition and structure. Afterwards the rubber stops were removed and the ends of the cylinders were sealed with plastic tape. The specimens were stored for over 6 months in a moist plastic box and then cut to cylinders with the size of $\varnothing 50 \times 75 \mathrm{~mm}$ for use as specimens in the experiments. In order to prevent carbonation, saturated lime water was used at the bottom of the plastic box as absorbent for carbon dioxides during the storage of specimens. To further ensure that the specimens used in the leaching experiments were not carbonated, the paste portions about $10-20 \mathrm{~mm}$ near the ends of the cylinders was cut off prior to the specimen cutting.

The mortar specimens at water- cement ratio of 0.5 and a cement: sand ratio of $1: 2$, were cast from mixtures of Swedish structural Portland cement for civil engineering (Table 1), deionized water and a siliceous natural sand with maximum particle size of $1 \mathrm{~mm}$. Similar casting procedure as of paste specimens was followed.

The concrete specimens were cast from mixtures of Swedish structural Portland cement for civil engineering, natural sand (the sand was a type of siliceous gravel with size of $0-8 \mathrm{~mm}$ and fineness modulus of 3.82, in accordance with European standard EN 933-1 (EN 933-1 Tests for geometrical properties of aggregates)) and crushed coarse aggregate with maximum size of $16 \mathrm{~mm}$. $65 \%$ of total aggregate content was fine aggregate $(0-8 \mathrm{~mm})$ and the rest was the course aggregate $(8-16 \mathrm{~mm})$. The course aggregate was an equal bland of (50\%), 8-12 $\mathrm{mm}$ and $12-16 \mathrm{~mm}$ of crushed aggregates. The specimens were cast in cylinders in two different dimensions of $\varnothing 100 \times 200 \mathrm{~mm}$ and $\varnothing 50 \times 250 \mathrm{~mm}$ with two different water cement W/C-ratios (according to the properties of the concrete used in the Final Repository for Short-lived Radioactive Waste, SFR, in Sweden (Emborg et al. 2007; Höglund 2001)). The observations from the slump test prior to casting was $25 \mathrm{~mm}$ for the concrete with $\mathrm{W} / \mathrm{C}=0.48$ and $35 \mathrm{~mm}$ for $\mathrm{W} / \mathrm{C}=0.62$. The specimens were demolded $24 \mathrm{~h}$ after casting and then cured in the saturated lime water for more than 3 months after which they were stored for over 3 months in a moist plastic box and then cut to cylinders with the dimensions of $\varnothing 50 \times 75$ and $\varnothing 100 \times 50 \mathrm{~mm}$ to be depleted in $\mathrm{Ca}$ in the leaching experiments.

The specifications of all the specimens such as mix proportions as well as cast sizes and cut sizes are presented in Table 2. It should be noted that the W/C-ratios for paste and mortar specimens were chosen as to obtain better homogenized mixes. However, as noted the concrete specimens were cast according to the used W/C-ratios used in repository of nuclear waste in Sweden, SFL. 
Table 1 Chemical characteristics of Swedish CEM I 42.5N MH/SR3/LA.

\begin{tabular}{c|c|c|c|c|c|c|c|c|c}
\hline $\begin{array}{c}\text { Chemical } \\
\text { formulation }\end{array}$ & $\mathrm{CaO}$ & $\mathrm{SiO}_{2}$ & $\mathrm{Al}_{2} \mathrm{O}_{3}$ & $\mathrm{Fe}_{2} \mathrm{O}_{3}$ & $\mathrm{MgO}$ & $\mathrm{Na}_{2} \mathrm{O}$ & $\mathrm{K}_{2} \mathrm{O}$ & $\mathrm{SO}_{3}$ & $\mathrm{Cl}$ \\
\hline \hline Percentage & 64 & 22.2 & 3.6 & 4.4 & 0.94 & 0.07 & 0.72 & 2.2 & 0.01 \\
\hline
\end{tabular}

Table 2 Cast specimen's specifications.

\begin{tabular}{|c|c|c|c|c|c|c|}
\hline Specimens & Cement type & $\mathrm{W} / \mathrm{C}$ & Aggregate fraction & $\begin{array}{c}\text { Cement content } \\
\left(\mathrm{kg} / \mathrm{m}^{3}\right)\end{array}$ & $\begin{array}{c}\text { Size of cast } \\
\text { specimens }(\mathrm{mm})\end{array}$ & $\begin{array}{l}\text { Size of specimens } \\
\text { after cutting }(\mathrm{mm})\end{array}$ \\
\hline Paste & \multirow{4}{*}{$\begin{array}{r}\text { CEM I 42.5 N } \\
\text { MH/SR3/LA }\end{array}$} & 0.5 & - & 1225 & \multirow[t]{2}{*}{$\varnothing 50 \times 250$} & \multirow[t]{2}{*}{$\varnothing 50 \times 75$} \\
\hline Mortar & & 0.5 & 0.5 & 635 & & \\
\hline \multirow[t]{2}{*}{ Concrete } & & 0.48 & 0.7 & 350 & \multirow{2}{*}{$\begin{array}{c}\varnothing 50 \times 250 \text { and } \\
\varnothing 100 \times 200\end{array}$} & \multirow{2}{*}{$\begin{array}{c}\varnothing 50 \times 75 \text { and } \\
\varnothing 100 \times 50\end{array}$} \\
\hline & & 0.62 & 0.7 & 300 & & \\
\hline
\end{tabular}

\subsection{Electrochemical Acceleration Method}

Concrete specimens were depleted in calcium by the use of a newly developed method for accelerated calcium leaching of solid specimens of flexible size (Babaahmadi et al. 2015). As illustrated in Fig. 1, a cementitious specimen acting as a porous medium for ion migration is placed between two electrolyte solutions. The electrical migration enables faster transport of calcium ions, whilst application of ammonium nitrate as catholyte enables higher rate of dissolution of calcium hydroxides. As of using lithium hydroxide solution as anolyte, the $\mathrm{pH}$ of the anolyte was always kept at 13.5-14 and as of using ammonium nitrate solution as catholyte, the $\mathrm{pH}$ of catholyte was around a $\mathrm{pH}$ level of around 9. The alkaline characteristic of anolyte solution prevented acid attach due to production of $\mathrm{H}^{+}$ions at the anode.
As it is concluded by Babaahmadi et al. (Babaahmadi et al. 2015), with a current density of $125-130 \mathrm{~A} / \mathrm{m}^{2}$ an approximately 53 days of experimental time is predicted to reach to complete leaching of Portlandite for a paste specimen of $\varnothing 50 \times 75 \mathrm{~mm}$ and W/C-ratio of 0.5 . In this study similar experimental time (53 days) was chosen for the specimens. It should be noted that depending on the W/Cratio the Portlandite content varies in the specimens. In this study the concrete specimens have the same volume of aggregate, implying the same volume of $\mathrm{CSH}$, Portlandite and capillary pores. Which means with a higher W/C- ratio, the capillary pore volume is larger, implying the $\mathrm{CSH}$ and Portlandite volume is smaller. Accordingly under the same degree of hydration, Portlandite in the concrete with higher $\mathrm{W} / \mathrm{C}$ is less. As a consequence the experimental time for concrete specimens with W/C-ratio of 0.62 to reach to

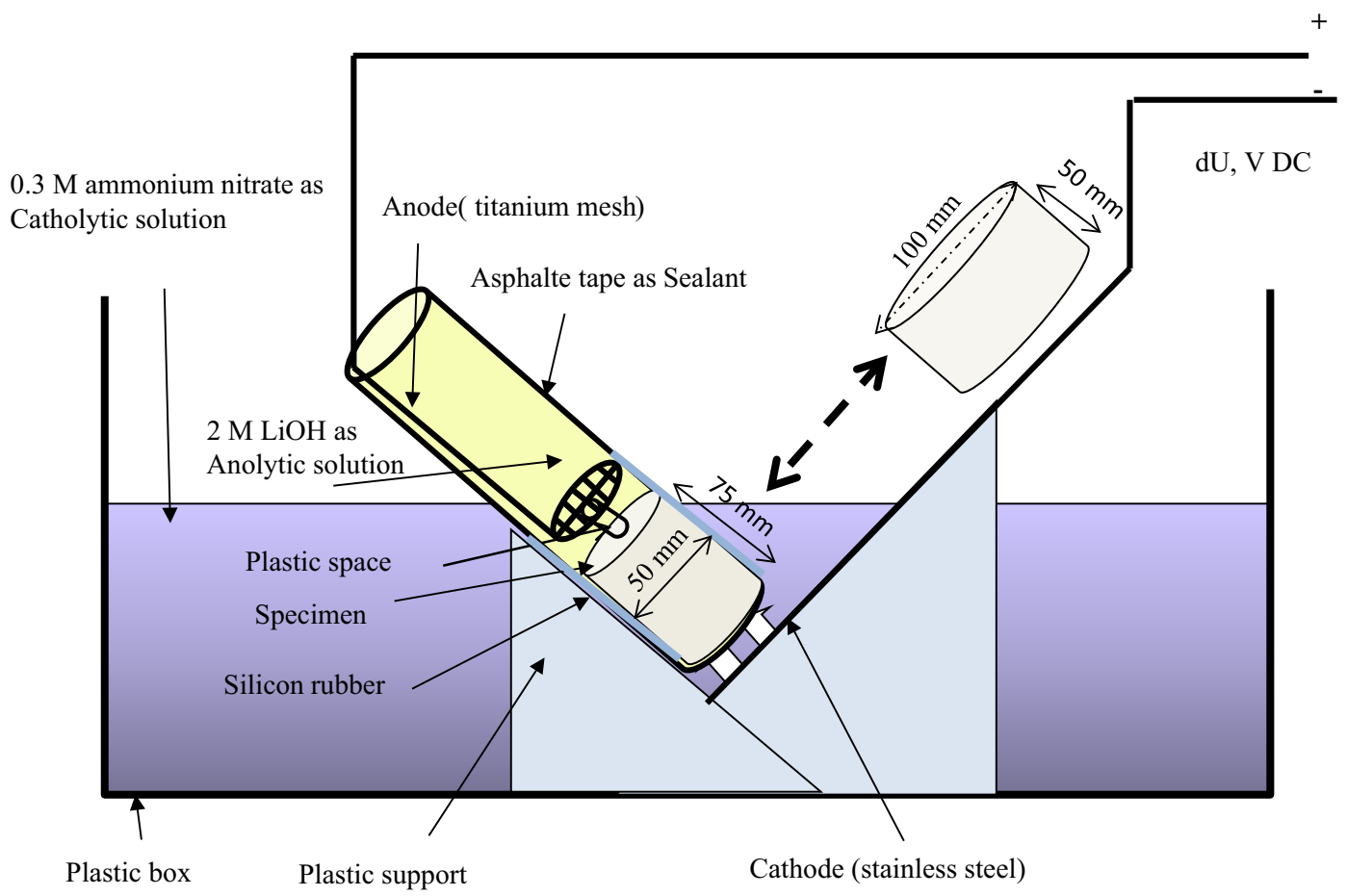

Fig. 1 Electrochemical migration set-up design. 
complete leaching of Portlandite should be shorter than that of specimens with W/C-ratio of 0.48 . However, the prolongation of experimental time after leaching of Portlandite only affects the phase changes in CSH gel and as it was concluded by Carde et al. the changes in $\mathrm{CSH}$ phases due to leaching is not affecting the mechanical properties (Carde et al. 1996).

\subsection{Natural Leaching Test}

The natural immersion test involved the immersion of the test specimen in groundwater to account for the leaching of calcium ions under relatively natural condition. This method is chosen as most of the reference natural leaching test methods introduced in the literature involve an immersion test with frequent exchanges of the leaching solution (Adenot and Buil 1992; Carde and François 1997; Faucon et al. 1996, 1998; Gustafson 2008; Haga et al. 2005; Heukamp et al. 2001; Langton and Kosson 2009; Mainguy et al. 2000; Maltais et al. 2004; Peyronnard et al. 2009; Revertegat et al. 1992; Ryu et al. 2002; Saito et al. 1992; Wittmann 1997).

In this study the specimens of $\varnothing 46 \times 100-250 \mathrm{~mm}$, cured for 6 months, were coated with thick (3-4 mm) epoxy, sealing all surfaces except one for exposure. The experiment was carried out in the Äspö laboratory in Oskarshamn, Sweden. The laboratory is located $400 \mathrm{~m}$ deep under the ground which could facilitate access to the groundwater. The specimens were placed in a container and immersed in the groundwater. The groundwater was exchanges continuously as it was flowing into the container with a tube, Fig. 2. After 2 and 3.5 years of exposure, samples were chemically analyzed in order to obtain their leaching profiles.

\subsection{Assessments of the Changes in Hydrated Phases Due to Decalcification}

Line scans quantifying the axial (longitudinal) changes in $\mathrm{Ca} / \mathrm{Si}$ ratios of solid samples were performed by Laser Ablation- Inductive Coupled Plasma- Mass Spectrometry (LA-ICP-MS). Laser Ablation analysis was performed using a New Wave NWR213 laser ablation system coupled to an Agilent 7500a quadrupole ICP-MS (upgraded with shield torch and a second rotary vacuum pump). A $30 \mu$ laser spot size, beam energy density of ca. $6 \mathrm{~J} / \mathrm{cm}^{2}$ and repetition rate of $10 \mathrm{~Hz}$ was used in line scan mode. Each analysis included background measurement for $30 \mathrm{~s}$, before switching on the laser. Figure 3, illustrates the cut samples used for the measurements. The surface of the cut sample was polished with a sand paper after saw cutting and later the sample was vacuum dried. An average of three line scans was used to report the results.

In order to characterize the changes in hydrated phases, especially Portlandite, in the leached specimens produced in this study thermogravimetry analysis (TGA) were performed with a Netzsch, STA 409 PC/PG. To perform the measurements powder samples were prepared out of leached specimens. For electrochemically leached specimens a longitudinal section as shown in Fig. 3 was cut from the specimen (paste, mortar and concrete) and hand crushed in a mortar and vacuum dried afterwards. However for the case
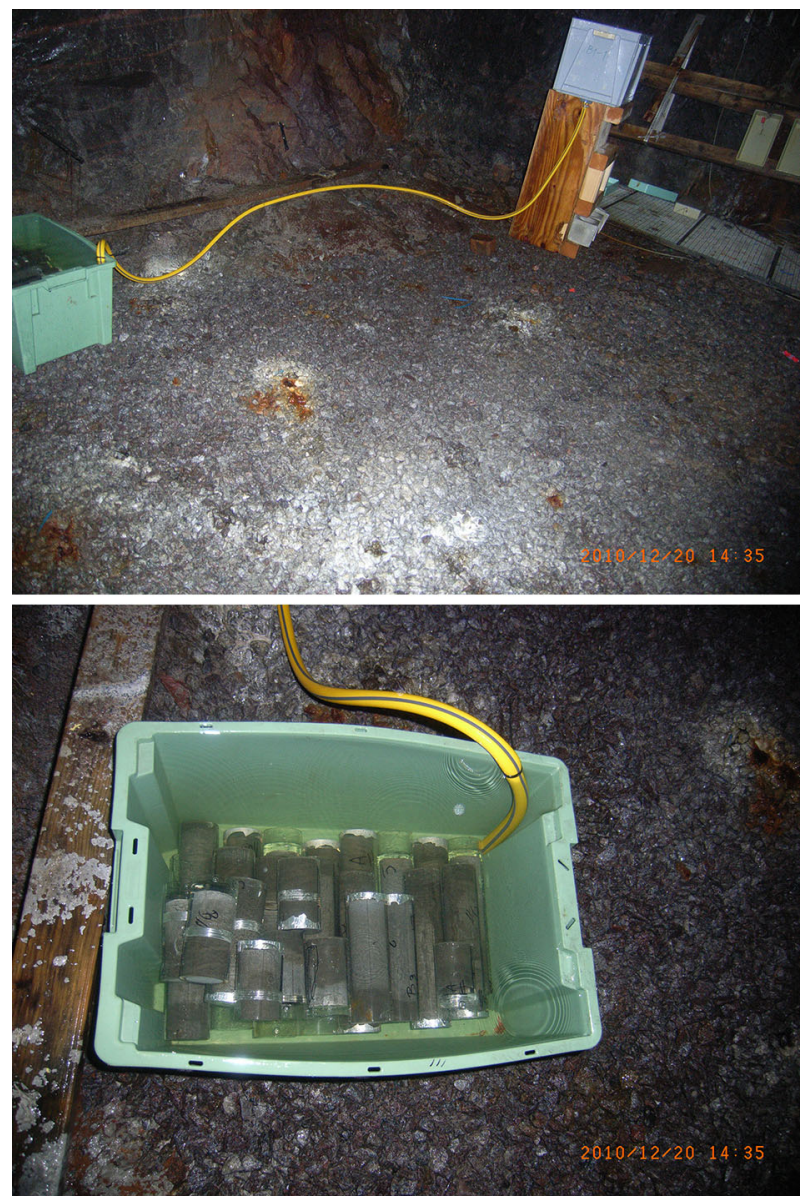

Fig. 2 Natural leaching test set-up.

of naturally leeched specimens the powders were prepared from the outermost $2 \mathrm{~mm}$ of the leaching front. The samples were placed in a crucible and heated in pure nitrogen (inlet flow rate of $20 \mathrm{ml} / \mathrm{min}$ ) to a set temperature of $900{ }^{\circ} \mathrm{C}$. The heating rate was a linear ramp of $10{ }^{\circ} \mathrm{C} / \mathrm{min}$.

\subsection{Transport Properties}

The gas permeability and capillary water absorption tests were performed according to state of the art report of RILEM Technical Committee 189-NEC (Torrent 2007). The measurements were performed on concrete specimen of the size $\varnothing 100 \times 50 \mathrm{~mm}$. The specimens were preconditioned for 2 weeks according to recommended procedures stated in RILEM technical committee 189-NEC (Torrent 2007) prior to the measurements. The step by step procedure for the preconditioning, measurements and instrument to carry out the measurements of gas permeability and capillary absorption of water is explained in 189-NEC standard.

The chloride diffusion coefficient of the pristine and leached specimens were studied by means of the rapid chloride migration test according to NT BUILD 492 described by Tang (NT BUILD 492, Concrete, Mortar and Cement-based Repair Materials: Chloride Migration Coefficient from Nonsteady-state Migration Experiments 1999; Tang 1996). For the calcium depleted specimens prediction of the duration of the experimental time was difficult due to that the increased porosity of the specimens as well as the reduced 

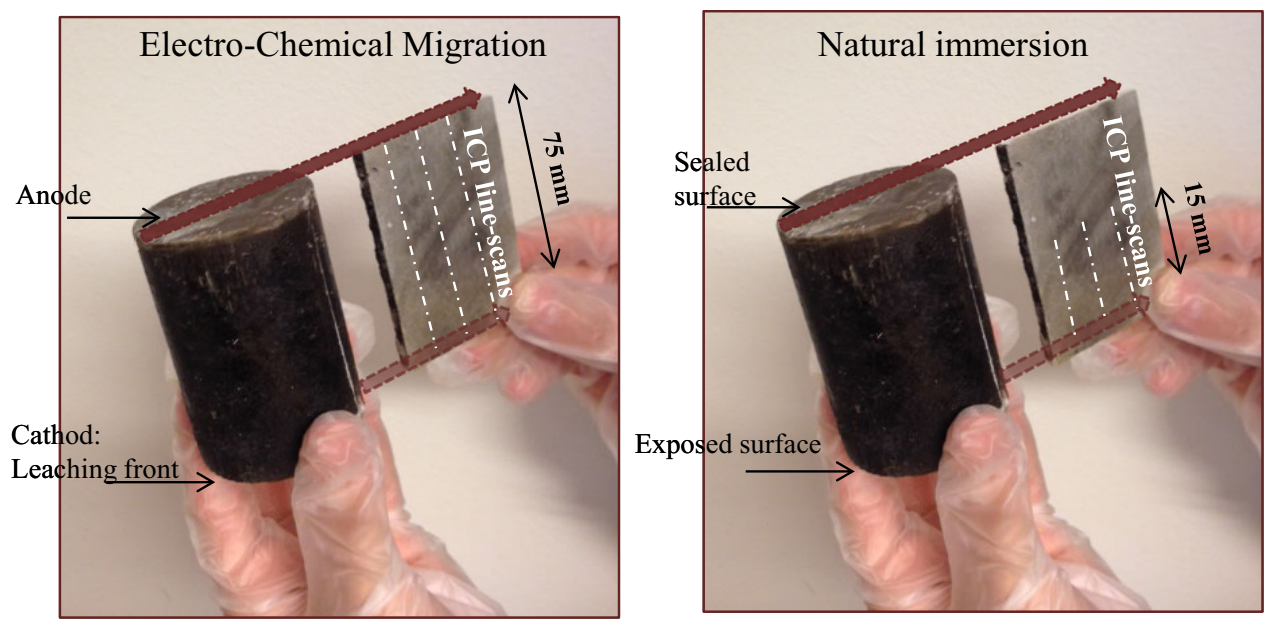

Fig. 3 Sample preparation for ICP-MS analysis.

concentration of chloride in the pore solution dramatically alters the chloride diffusion rate. Here the duration of the experiments were reduced to $15 \mathrm{~h}$ compared to fresh concrete specimens for which a duration of $24 \mathrm{~h}$ is normally used (NT BUILD 492, Concrete, Mortar and Cement-based Repair Materials: Chloride Migration Coefficient from Nonsteady-state Migration Experiments 1999; Tang 1996). However, in spite of the large reduction in experimental time, chloride ions penetrated through the entire thickness of the specimens during this experiment. For that reason, no exact value of the chloride diffusion rate could be obtained but instead the minimum chloride diffusion coefficient was calculated for the calcium depleted concrete specimens.

\subsection{Mechanical Properties}

The tensile strength of the leached and reference concrete specimens of size $\varnothing 100 \times 50 \mathrm{~mm}$ was measured using the splitting test on a Toni-Technik compression testing machine with a maximum capacity of $100 \mathrm{kN}$. The test procedure is in accordance with American standard ASTM C49 (ASTM C496/C496M-11, Standard Test Method for Splitting Tensile Strength of Cylindrical Concrete Specimens). The compressive strength of concrete, mortar and paste specimens of size $\varnothing 50 \times 75 \mathrm{~mm}$ was measured with same compression testing machine and according to ASTM C39 standard (ASTM C39/C39M-14a, Standard Test Method for Compressive Strength of Cylindrical Concrete Specimens). According to this standard a correction factor of 0.96 was applied to the compressive strength results to account for the length:dimater ratio which is lower than 1.75. The calcium depleted specimens were kept in $100 \%$ RH until being tested in order to avoid any internal cracks.

Elastic modulus of the concrete specimens of size $\varnothing 50 \times 75 \mathrm{~mm}$ was obtained as the slope of stress-strain curves recorded by means of an ALPHA compression testing machine. The load cell had a maximum capacity of $50 \mathrm{kN}$ and was loaded with a mechanical press at a constant rate of $0.01 \mathrm{kN} / \mathrm{ms}$. The vertical strain was measured utilizing a calibrated Linear Variable Differential Transformers (LVDT) sensor. The end surfaces of the specimens, perpendicular to the longitudinal axis of specimen, were cut with a diamond saw and polished in order to create a smooth surface. The concrete specimens of the size $\varnothing 50 \times 75 \mathrm{~mm}$ were placed between two platens and positioned under the load cells. 4 LVDT sensors were used to measure the displacement of the bottom platen and three more sensors were employed to measure the displacement of the upper platen. The sensors were connected to a data-log system to record the gradient of strain as a function of stress.

An impact resonant apparatus was used to measure the fundamental longitudinal frequency of concrete, mortar and paste specimens of the size $\varnothing 50 \times 75 \mathrm{~mm}$. One end of the horizontally placed concrete cylinder was vibrated with an impactor and the other end was connected to an accelerometer. The accelerometer was connected to an amplifier and the set-up was connected to a wave form analyzer. The waveform analyzer shall have a sampling rate of at least $20 \mathrm{kHz}$ and should record at least 1024 points of the wave form. By utilizing the fact that the elastic modulus is proportional to the square root of the resonant frequency the elastic modulus of each specimen can be calculated according to American standard ASTM C215. The dynamic elastic modulus was calculated according to Eq. (1).

$$
E=D \times M \times\left(n^{\prime}\right)^{2}
$$

where $E$ is the dynamic elastic modulus, $M$ is the mass and $n^{\prime}$ is the fundamental longitudinal frequency and $D$ is a factor defined according to Eq. (2) for cylindrical specimens.

$$
D=5.093 \times\left(L / d^{2}\right)
$$

The values from this non-destructive test can be compared with those obtained according to stress-strain curves.

\section{Results and Discussions}

\subsection{Characterization of Degraded Specimens}

The LA-ICP-MS results, presenting the electrochemicalmigration-induced longitudinal change in the $\mathrm{Ca} / \mathrm{Si}$ ratio of the leached paste specimen are illustrated in Fig. 4. As can be seen, ICP-MS line scans representing the composition of 
leaching front in degraded specimens leached with electrochemical migration and natural immersion test methods are illustrated. It is shown that the propagation of leaching front (shape of leaching front) obtained by the two methods are relatively comparable and the longitudinal changes in the $\mathrm{Ca} / \mathrm{Si}$ ratio propagates towards a homogeneous leaching state in time, indicating a complete leaching of Portlandite.

Moreover, as shown after approximately 53 days of experimental time $\left(1.2 \times 10^{6}\right.$ Coulombs $)$, a $\mathrm{Ca} / \mathrm{Si}$ ratio close to complete leaching of Portlandite is obtained in electrochemically leached specimens, while the naturally leached specimens indicate up to $10 \mathrm{~mm}$ of leaching front in 3.5 years of leaching. This indicates that considerable acceleration rate is gained with application of electrochemical migration method. Similar outcome can be obtained when comparing the specimen size and leaching duration in electro-chemical migration test and leaching experiments reported in the literature. Haga et al. (2005) have shown that a depletion depth of a maximum of $1.25 \mathrm{~mm}$ can be expected after 100 days of a natural immersion test. Faucon et al. (1998) reported that up to 60 days of natural leaching leads to $0.7 \mathrm{~mm}$ of dissolved thickness in exposed specimens. Lagerblad (2001) and Trägårdh and Lagerblad (1998) reported a leaching depth equal to 5-10 $\mathrm{mm}$ can be expected after up to 100 years. Heukamp et al. (2001) used specimens with the size of $\varnothing 11.5 \times 60 \mathrm{~mm}$ for a leaching period of 45 days. Nguyen et al. (2007) have reported on the application of specimens of $\varnothing 32 \times 100 \mathrm{~mm}$ and $\varnothing 110 \times 220$ for an experimental time of up to 547 days and Choi and Yang (2013), have used



Fig. 4 LA-ICP-MS analysis for naturally and accelerated leached samples. 
cylindrical concrete samples of $\varnothing 100 \times 100 \mathrm{~mm}$ for an experimental time of up to 365 days.

Further, the TGA analyses results are presented in Fig. 5 comparing temperature-induced mass changes for reference, accelerated leached and naturally leached paste samples. It should be noted that for the case of natural leaching the samples were taken from 0 to $2 \mathrm{~mm}$ of the outer most part of the exposed surface. As can be seen, the reference sample exhibits a mass change at approximately $400{ }^{\circ} \mathrm{C}$, which is the assigned peak to the Portlandite (Zhang and Ye 2012). However for all degraded samples no matter if leached naturally or with the acceleration method the Portlandite peaks are vanished. The preferential leaching of Portlandite due to decalcification has been also stated in literature
(Adenot and Buil 1992). This is also an indication that the electrochemical migration method enables leaching of cementitious specimens even when containing aggregates.

The average changes in the mass of concrete specimens representing the changes in the bulk density and eventually changes in porosity are presented in Table 3. As shown the specimens with a lower W/C-ratio are indicating higher degree of mass changes after leaching. Moreover, the changes in porosity according to total leached content of Portlandite are also presented. The results are in accordance with explanations in Sect. 2.2, stating that with a lower W/C-ratio a larger Portlandite content is expected and moreover, it is shown that the mass depletion due to leaching is mainly attributed to leaching of Portlandite. Accordingly a
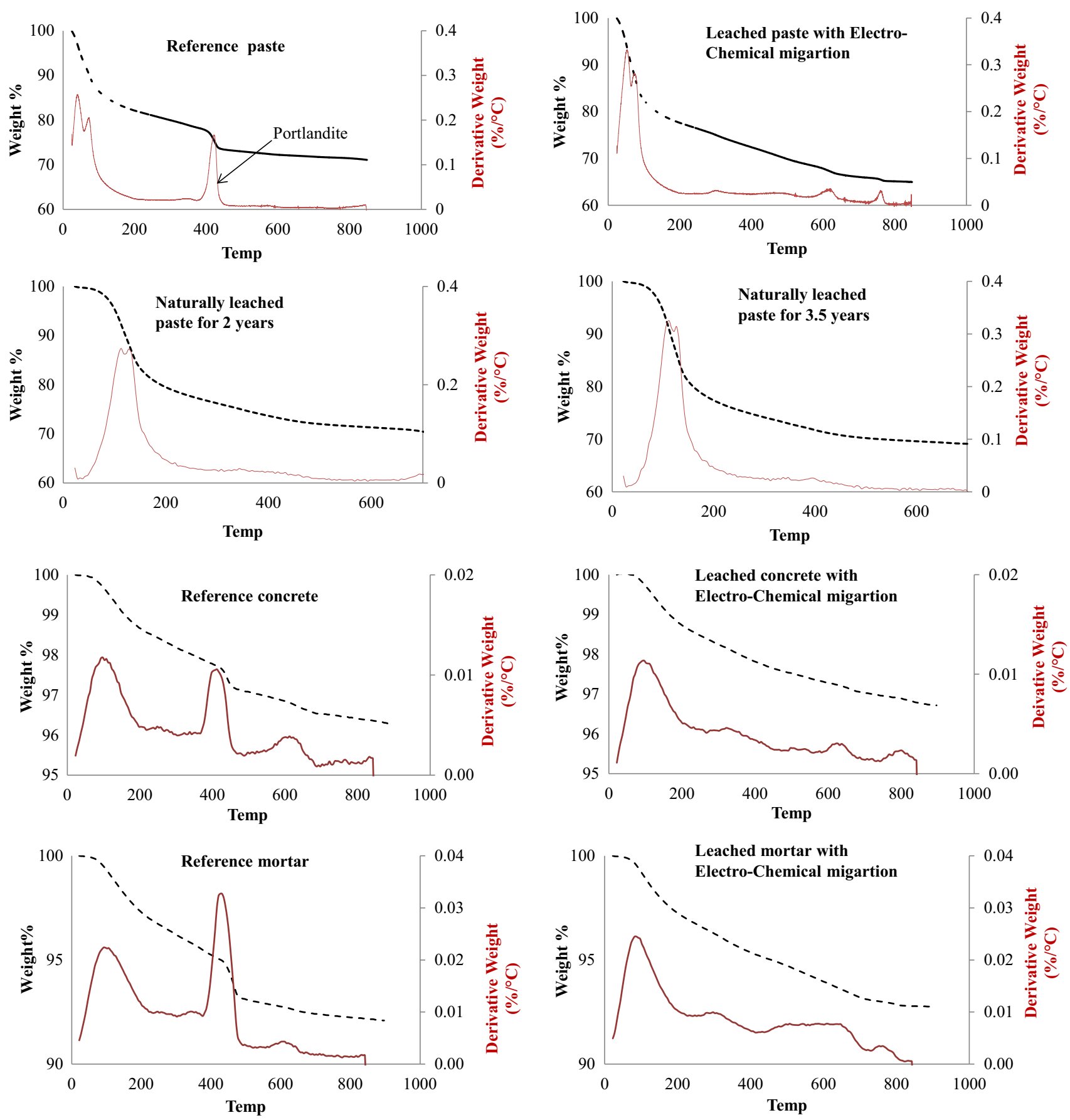

Fig. 5 TGA analysis for reference and degraded paste samples. 
higher degree of mass change will be attained. It should be noted that the specimens were pre-conditioned according to the state of the art report of RILEM Technical Committee 189-NEC (Torrent 2007), before weighting to have a comparable moisture condition.

\subsection{Transport Properties}

The capillary water absorption results representing the changes in pore structures of the specimens are presented on the left side of Fig. 6. Considering the presented results it can be inferred that the capillary water absorption in $24 \mathrm{~h}$ is increased by a factor of 4 and 2 for calcium depleted specimens with W/C-ratios of 0.48 and 0.62 , respectively. As can be seen that the difference in rate of capillary water absorption of aged specimens with different water cement ratios, is much less than that of reference specimens. This indicates that a very similar pore structure is expected in aged specimens no matter which initial W/C-ratio the specimens had.

Further, the change in gas permeability coefficient due to degradation is presented in the right side of Fig. 6. As illustrated the gas permeability in the calcium depleted specimens is more than 10 times higher than in the pristine material. This can be explained by the larger porosity after decalcification. Furthermore, the changes in chloride migration coefficient of the concrete specimens due to degradation are presented in Fig. 7. As it can be seen, at least three times higher chloride migration coefficient is expected after calcium depletion. It should be noted that the presented results regarding the calcium depleted specimens are the minimum chloride migration coefficient due to the full penetration through the specimen thickness as it was pointed out previously. The results are in good agreement with the results presented Choi and Yang (2013).

\subsection{Mechanical Properties}

The average tensile strength of concrete specimens of size $\varnothing 100 \times 50 \mathrm{~mm}$ are presented in Fig. 8. As shown the average tensile strength for the specimens with a W/C-ratio of 0.48 is reduced by up to approximately $70 \%$ due to calcium depletion whereas the reduction in tensile strength for the specimen with a W/C-ratio of 0.62 is about $55 \%$.
Further, the average compressive strength results for specimens of size $\varnothing 50 \times 75 \mathrm{~mm}$ is presented in Fig. 9. As it can be seen the reduction in compressive strength due to leaching is $70 \%$ for concrete specimens with $\mathrm{W} / \mathrm{C}=0.48$, $59 \%$ for concrete specimens with $\mathrm{W} / \mathrm{C}=0.62,74 \%$ for mortar specimens and $56 \%$ for paste specimens. Interestingly the residual strength of the Ca-depleted concrete specimens is very similar regardless of the water cement ratios of the original specimens. This can also be seen for paste and mortar specimens. This indicates that when leaching propagates towards an approximate complete leaching of the Portlandite, comparable strength properties can be expected for samples with different original W/Cratios. This is due to comparable pore structures that are obtained in the specimens after leaching. It has also been shown in literature that the changes in pore structure have a detrimental influence on the strength properties of cementitious materials (Carde et al. 1996; Haga et al. 2005; Mainguy et al. 2000).

The findings presented above are in good agreement with the conclusions presented by (Carde et al. 1996). In their study they showed that the loss of strength due to complete removal of Portlandite can be up to $70 \%$. Similar results have also been presented by (Choi and Yang 2013). Moreover, rate of change in the strain of the concrete specimens as a function of applied stress representing stress-strain curves is presented in Fig. 10. As shown the elastic modulus is represented by the slope of the stress-strain curves is reduced by up to $40 \%$ after leaching for both types of specimens. In addition, to confirm the credibility of the results from stress-strain curves, elastic modulus was also estimated through measuring the natural frequency of the specimens. The results which are presented in Table 4 are comparable with the results presented in Fig. 10.

\section{Conclusions}

In this paper a study of mechanical and physical properties of concrete specimens which are depleted in calcium by a newly developed acceleration method is presented. Providing such results requires calcium depleted concrete

Table 3 Mass changes due to leaching for concrete specimens of size $\varnothing 100 \times 50 \mathrm{~mm}$.

\begin{tabular}{c|c|c|c|c|c|c|c}
\hline & REF (g) & Aged (g) & Mass depletion & V depletion & Porosity change $^{\mathrm{b}}$ & \begin{tabular}{c} 
Leached $_{\text {portlandite }(\mathrm{g})^{\mathrm{c}}}$ \\
\hline \hline $\mathrm{W} / \mathrm{C}=0.48$
\end{tabular} Porosity change $^{\mathrm{d}}$ \\
\hline $\mathrm{W} / \mathrm{C}=0.62$ & 907 & 881 & 46.00 & 20.81 & 5.3 & 44.4 & 5.12 \\
\hline
\end{tabular}

\footnotetext{
${ }^{a}$ Calculated assuming that total mass change is attributed to Portlandite depletion (V depletion = mass change/Portlandite density).

${ }^{\mathrm{b}}$ Calculated according to $\mathrm{V}$ depletion and considering the dimension of the specimens, $\varnothing 100 \times 50 \mathrm{~mm}$ (Porosity Change $=\mathrm{Vdepletion} /$ total volume of specimen).

${ }^{\mathrm{c}}$ Leached Portlandite is according to measured leached calcium content in catholyte solution.

${ }^{\mathrm{d}}$ Calculated according to total leached Portlandite and considering the dimension of the specimens $(\varnothing 100 \times 50 \mathrm{~mm})$.
} 

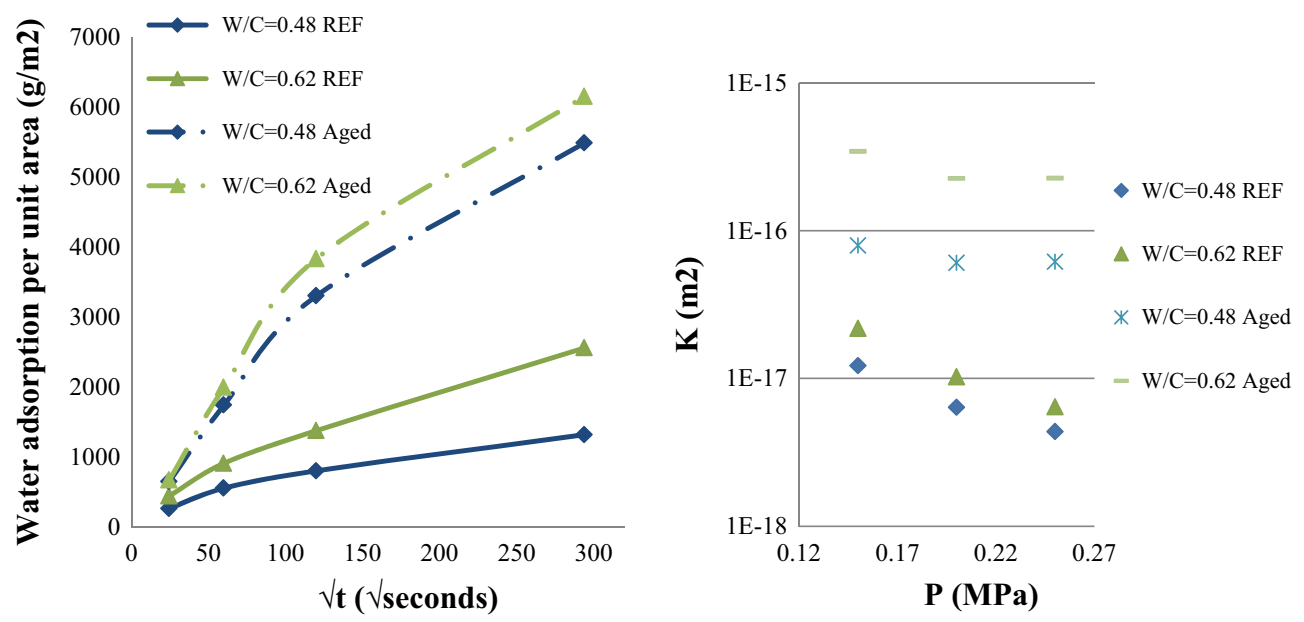

Fig. 6 Capillary water absorption for concrete specimens for W/C ratios of 0.48 and 0.62 before and after leaching of calcium (left) and Gas permeability coefficient $\mathrm{K}$ as function of applied absolute gas pressure $\mathrm{P}$ (right).

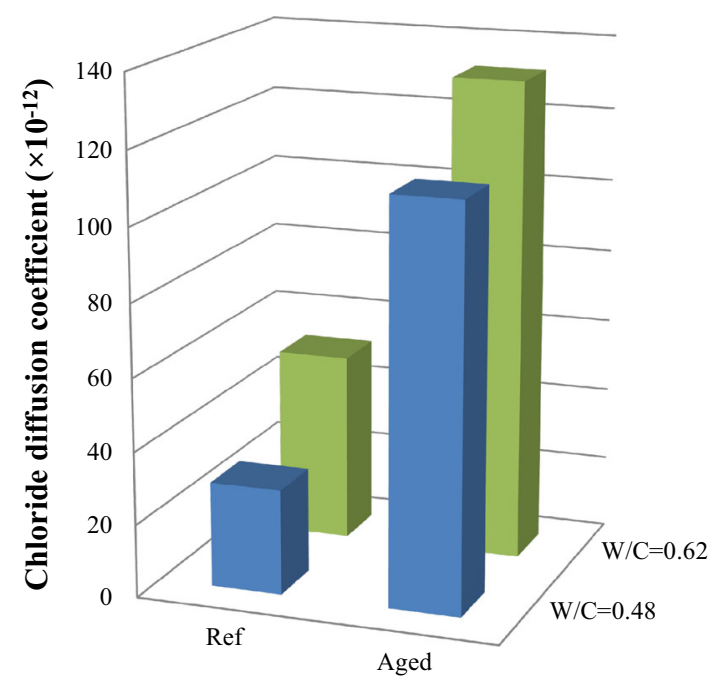

Fig. 7 Chloride diffusion coefficient for reference and aged concrete specimens. The calculated diffusion coefficient for the case of aged specimens is the least possible value. Measuring the highest possible value is not practically possible due to very high porosity of the specimens.

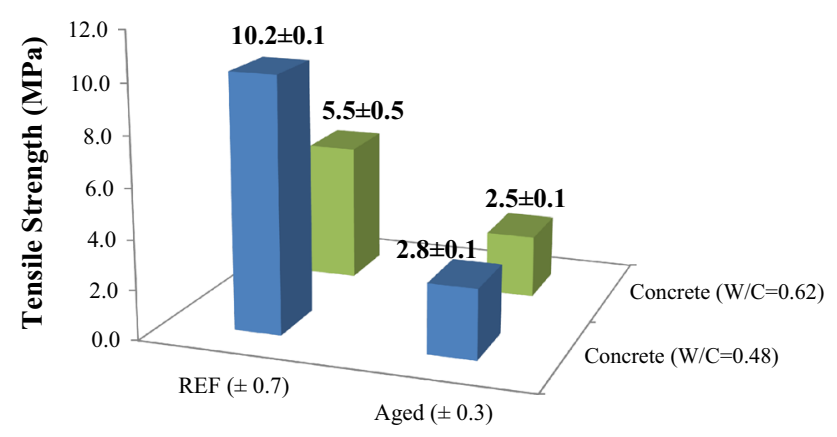

Fig. 8 Tensile strength results.

specimens of proper sizes. The presented method is shown to be effective producing decalcified concrete specimens of flexible size. The changes in properties such as tensile and

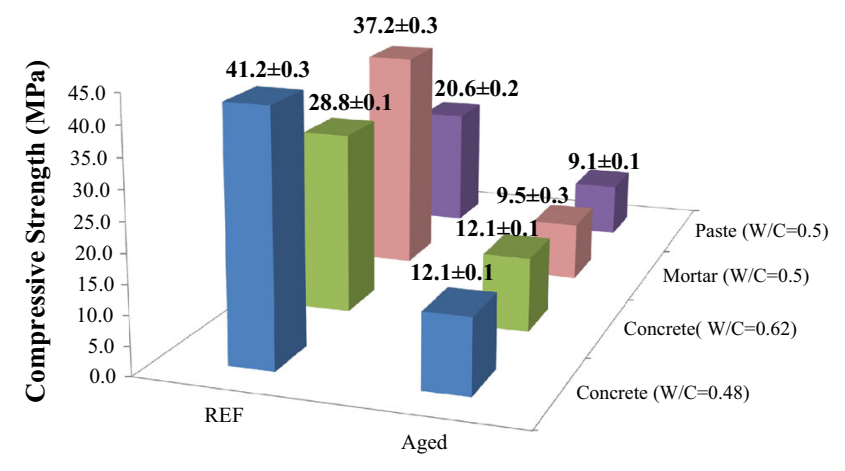

Fig. 9 Compressive strength results.

compressive strength, elastic modulus, gas permeability as well as chloride diffusion coefficient are taken into consideration. One of the direct applications of this study is to provide experimental approaches to be able to validate the risk assessment analyses regarding the functionality of engineered cementitious barriers. Based on the results presented in this study the following conclusions can be drawn:

- The electrochemically-induced leaching is not affected by the aggregate content in mortar or paste specimens.

- Leaching of Portlandite causes considerable changes in physical and mechanical properties of concrete specimen, primary due to the increase in pore volume. It was concluded that larger pore volume due to complete leaching of portlandite can be expected which would cause up to $70 \%$ decrease in mechanical strength and $40 \%$ decrease in elastic modulus.

- Larger pore volume after degradation causes more than 10 times increase in gas permeability and at least 3 times higher chloride diffusion rate.

- The residual strength properties of the concrete specimens after complete leaching of portlandite are shown to be relatively similar no matter which initial water cement ratios the specimens have. This is to great extent due to similar pore structures in concrete specimens after leaching. 

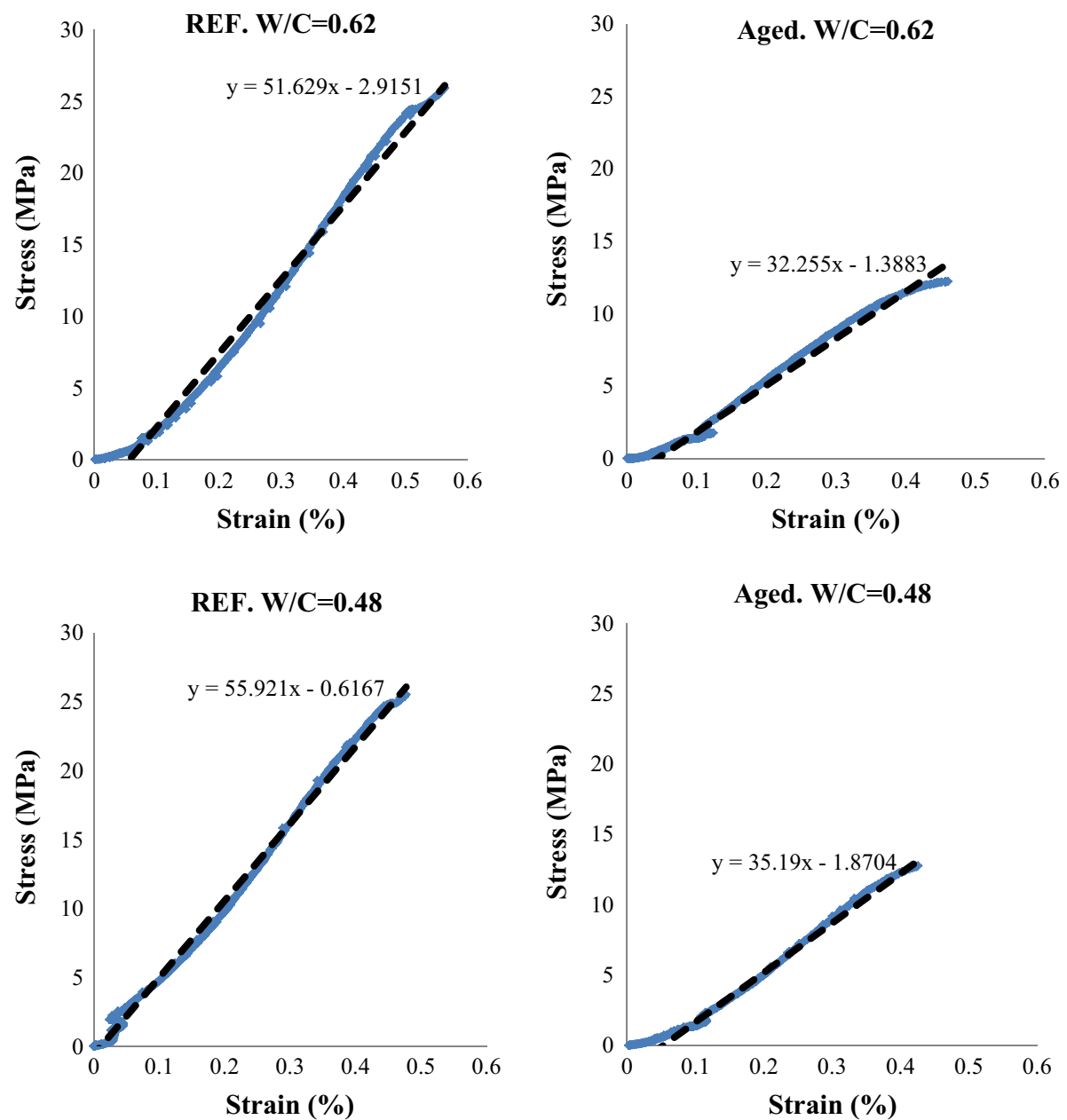

slope of the curves $=$ Elastic modulus

Fig. 10 Stress-strain curves for concrete specimens.

Table 4 Natural frequency and calculated E-modulus of the reference and aged specimens.

\begin{tabular}{c|c|c|c|c|c|c|c|c|c}
\hline \multirow{2}{*}{} & & \multicolumn{2}{|c|}{ Mass $(\mathrm{g})$} & \multicolumn{2}{c|}{ Length $(\mathrm{m})$} & \multicolumn{2}{c}{ F (kHz) } & \multicolumn{2}{c}{ E (GPa) } \\
\cline { 3 - 11 } & & Ref & Aged & Ref & Aged & Ref & Aged & Ref & Aged \\
\hline \hline \multirow{2}{*}{ Concrete } & W/C $=0.48$ & 390 & 325 & 0.078 & 0.078 & 27.4 & 21.6 & 46.5 & 24.1 \\
\cline { 2 - 12 } & W/C $=0.62$ & 350 & 330 & 0.076 & 0.075 & 29.3 & 22.1 & 46.5 & 24.6 \\
\hline Mortar & W/C $=0.5$ & 323 & 326 & 0.072 & 0.076 & 25.7 & 17.6 & 30.4 & 15.18 \\
\hline Paste & W/C $=0.5$ & 230 & 220 & 0.076 & 0.08 & 17.6 & 13.2 & 11.4 & 6.24 \\
\hline
\end{tabular}

\section{Acknowledgments}

The authors greatly appreciate financial support from Swedish Nuclear Fuel and Waste Management Company (SKB). Assistance with mechanical tests, BET and MIP analysis by Lars Wahlström, Ann Wendel and Liu Wei respectively are hereby appreciated and acknowledged.

\section{Open Access}

This article is distributed under the terms of the Creative Commons Attribution 4.0 International License (http://creative commons.org/licenses/by/4.0/), which permits unrestricted use, distribution, and reproduction in any medium, provided you give appropriate credit to the original author(s) and the source, provide a link to the Creative Commons license, and indicate if changes were made.

\section{References}

Adenot, F., \& Buil, M. (1992). Modelling of the corrosion of the cement paste by deionized water. Cement and Concrete Research, 22, 489-496. doi:10.1016/0008-8846(92)90092-a. ASTM C39/C39M-14a, Standard Test Method for Compressive Strength of Cylindrical Concrete Specimens. 
ASTM C496/C496M-11, Standard Test Method for Splitting Tensile Strength of Cylindrical Concrete Specimens.

Babaahmadi, A., Tang, L., Abbas, Z., Zack, T., \& Mårtensson, P. (2015). Development of an electro-chemical accelerated ageing method for leaching of calcium from cementitious materials. Materials and Structures. doi:10.1617/s11527015-0531-8

Berner, U. R. (1992). Evolution of pore water chemistry during degradation of cement in a radioactive waste repository environment. Waste Management, 12, 201-219. doi: 10.1016/0956053x(92)90049-o.

Carde, C., Escadeillas, G., \& François, R. (1997). Use of ammonium nitrate solution to simulate and accelerate the leaching of cement pastes due to deionized water. Magazine of Concrete Research, 49, 295-301.

Carde, C., \& François, R. (1997). Effect of the leaching of calcium hydroxide from cement paste on mechanical and physical properties. Cement and Concrete Research, 27, 539-550. doi:10.1016/s0008-8846(97)00042-2.

Carde, C., François, R., \& Torrenti, J.-M. (1996). Leaching of both calcium hydroxide and C-S-H from cement paste: Modeling the mechanical behavior. Cement and Concrete Research, 26, 1257-1268. doi:10.1016/0008-8846(96)00 095-6.

Choi, Y. S., \& Yang, E. I. (2013). Effect of calcium leaching on the pore structure, strength, and chloride penetration resistance in concrete specimens. Nuclear Engineering and Design, 259, 126-136. doi:10.1016/j.nucengdes.2013. 02.049 .

Emborg, M., Jonasson, J. E., \& Knutsson, S. (2007) Long-term stability due to freezing and thawing of concrete and bentonite at the disposal of low and intermediate level nuclear waste in SFR 1 (in Swedish) vol. R-07-60. SKB Technical Report R-07-60, Swedish Nuclear and Waste Management Company

EN 933-1 Tests for geometrical properties of aggregates.

Faucon, P., Adenot, F., Jacquinot, J. F., Petit, J. C., Cabrillac, R., \& Jorda, M. (1998). Long-term behaviour of cement pastes used for nuclear waste disposal: Review of physicochemical mechanisms of water degradation. Cement and Concrete Research, 28, 847-857. doi:10.1016/s00088846(98)00053-2.

Faucon, P., Le Bescop, P., Adenot, F., Bonville, P., Jacquinot, J. F., Pineau, F., \& Felix, B. (1996). Leaching of cement: Study of the surface layer. Cement and Concrete Research, 26, 1707-1715. doi:10.1016/S0008-8846(96)00157-3.

Gustafson, G., Hagström, M., \& Abbas, Z. (2008). Beständighet av cementinjektering

Haga, K., Sutou, S., Hironaga, M., Tanaka, S., \& Nagasaki, S. (2005). Effects of porosity on leaching of $\mathrm{Ca}$ from hardened ordinary Portland cement paste. Cement and Concrete Research, 35, 1764-1775. doi:10.1016/j.cemconres.2004. 06.034 .

Heukamp, F. H., Ulm, F. J., \& Germaine, J. T. (2001). Mechanical properties of calcium-leached cement pastes: Triaxial stress states and the influence of the pore pressures. Cement and Concrete Research, 31, 767-774.
Hinsenveld, M. (1992). A shrinkage core model as a fundamental representation of leaching mechanism in cement stabilized waste. Doctoral thesis, University of Cincinnati, Cincinnati, $\mathrm{OH}$.

Höglund, L.-O. (2001). Project SAFE: Modeling of long-term concrete degradation processes in the Swedish SFR repository vol R-01-08. SKB Report, Svensk Kärnbränslehantering $\mathrm{AB}$.

Lagerblad, B. (2001). Leaching performance of concrete based on studies of sample from old concrete constructions, TR01-27. Stockholm, Sweden: Swedish Nuclear Fuel and Waste Management.

Langton, C., \& Kosson, D. (2009). Review of mechanistic understanding and modeling and uncertainty analysis methods for predicting cementitious barriers performance. doi: $10.2172 / 974326$

Mainguy, M., Tognazzi, C., Torrenti, J.-M., \& Adenot, F. (2000). Modelling of leaching in pure cement paste and mortar. Cement and Concrete Research, 30, 83-90. doi: 10.1016/S0008-8846(99)00208-2.

Maltais, Y., Samson, E., \& Marchand, J. (2004). Predicting the durability of Portland cement systems in aggressive environments-Laboratory validation. Cement and Concrete Research, 34, 1579-1589. doi:10.1016/j.cemconres.2004. 03.029 .

Marinoni, N., Pavese, A., Voltolini, M., \& Merlini, M. (2008). Long-term leaching test in concretes: An X-ray powder diffraction study. Cement \& Concrete Composites, 30, 700-705. doi:10.1016/j.cemconcomp.2008.05.004.

Morga, M., \& Marano, G. C. (2015). Chloride penetration in circular concrete columns. International Journal of Concrete Structures and Materials, 9, 173-183. doi: 10.1007/s40069-014-0095-y.

Nguyen, V. H., Colina, H., Torrenti, J. M., Boulay, C., \& Nedjar, B. (2007). Chemo-mechanical coupling behaviour of leached concrete: Part I: Experimental results. Nuclear Engineering and Design, 237, 2083-2089. doi:10.1016/j .nucengdes.2007.02.013.

NT BUILD 492. (1999). Concrete, mortar and cement-based repair materials: Chloride migration coefficient from nonsteady-state migration experiments.

Park, S., \& Choi, Y. (2012). Influence of curing-form material on the chloride penetration of off-shore concrete. International Journal of Concrete Structures and Materials, 6, 251-256. doi:10.1007/s40069-012-0026-8.

Peyronnard, O., Benzaazoua, M., Blanc, D., \& Moszkowicz, P. (2009). Study of mineralogy and leaching behavior of stabilized/solidified sludge using differential acid neutralization analysis: Part I: Experimental study. Cement and Concrete Research, 39, 600-609. doi:10.1016/j.cemconres. cemconres.2009.03.016.

Pham, S., \& Prince, W. (2014). Effects of carbonation on the microstructure of cement materials: influence of measuring methods and of types of cement. International Journal of Concrete Structures and Materials, 8, 327-333. doi: 10.1007/s40069-014-0079-y.

Pritzl, M., Tabatabai, H., \& Ghorbanpoor, A. (2014). Laboratory evaluation of select methods of corrosion prevention in 
reinforced concrete bridges. International Journal of Concrete Structures and Materials, 8, 201-212. doi:10.1007/ s40069-014-0074-3.

Reardon, E. J. (1992). Problems and approaches to the prediction of the chemical composition in cement/water systems. Waste Management, 12, 221-239. doi:10.1016/0956-053 $\mathrm{x}(92) 90050-\mathrm{s}$.

Revertegat, E., Richet, C., \& Gégout, P. (1992). Effect of pH on the durability of cement pastes. Cement and Concrete Research, 22, 259-272. doi:10.1016/0008-8846(92)90064-3.

Ryu, J.-S., Otsuki, N., \& Minagawa, H. (2002). Long-term forecast of $\mathrm{Ca}$ leaching from mortar and associated degeneration. Cement and Concrete Research, 32, 1539-1544. doi:10.1016/s0008-8846(02)00830-x.

Saito, H., \& Deguchi, A. (2000). Leaching tests on different mortars using accelerated electrochemical method. Cement and Concrete Research, 30, 1815-1825. doi:10.1016/S00088846(00)00377-X.

Saito, H., Nakane, S., Ikari, S., \& Fujiwara, A. (1992). Preliminary experimental study on the deterioration of cementitious materials by an acceleration method. Nuclear Engineering and Design, 138, 151-155. doi:10.1016/ 0029-5493(92)90290-c.

Sellier, A., Buffo-Lacarrière, L., Gonnouni, M. E., \& Bourbon, X. (2011). Behavior of HPC nuclear waste disposal structures in leaching environment. Nuclear Engineering and Design, 241, 402-414. doi:10.1016/j.nucengdes.2010. 11.002 .

Tang, L. (1996). Electrically accelerated methods for determining chloride diffusivity in concrete-Current development. Magazine of Concrete Research, 48, 173-179.

Trägårdh, J., \& Lagerblad, B. (1998). Leaching of 90-year old concrete in contact with stagnant water, TR 98-11. Stockholm, Sweden: Swedish Nuclear fuel and Waste.

Torrent, R. (2007). Non-destructive evaluation of the penetrability and thickness of the concrete cover-State-of-the-Art Report of RILEM Technical Committee 189-NEC vol rep040.

Ulm, F.-J., Lemarchand, E., \& Heukamp, F. H. (2003). Elements of chemomechanics of calcium leaching of cementbased materials at different scales. Engineering Fracture Mechanics, 70, 871-889. doi:10.1016/s0013-7944(02) 00155-8.

Wittmann, F. H. (1997). Corrosion of cement-based materials under the influence of an electric field. Materials Science Forum, 247, 107-126. doi:10.4028/www.scientific.net/MSF. 247.107.

Zhang, Q., \& Ye, G. (2012). Dehydration kinetics of Portland cement paste at high temperature $J$ Therm Anal Calorim, 110, 153-158. doi:10.1007/s10973-012-2303-9. 